\title{
Learner Characteristics and Motivation: How to Achieve Efficient and Effective Learning
}

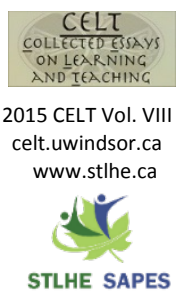

STLHE SAPES

\author{
Catherine Marie Fraser Bates \\ Queens University
}

During the Society for Teaching and Learning in Higher Education Conference 2014, a workshop was held three consecutive times as part of the Pedagogical Speed Dating sessions to introduce experienced college/university faculty and instructional designers to an approach to instructional design that is based on increasing motivation. The purpose of the workshop was to demonstrate the use of Keller's ARCS Model of Instructional Design for Motivation, specifically how to achieve effective learner/learner, learner/content, and learner/teacher interaction. The discussion focusses on the experiences of typical university and college students.

\section{Introduction}

Aim

$T$ his paper is based on a 30 minute workshop delivered in three consecutive sessions at the Society for Teaching and Learning in Higher Education Conference 2014 as part of the Pedagogical Speed Dating sessions. The aim of the session was to explore instructional design as a method of matching learner/teacher characteristics (motivation, experience, age, attitude, learning style, and background education) to the content. The context for the discussion was motivation of the typical university and college student with the objective to make recommendations for instructional strategies that would suit their characteristics. Constructivist conditions for learning was the frame within which the discussion was held.

\section{Background}

The use of the traditional lecture method is still prevalent in many universities and colleges today. The lecture method is a viable instructional strategy for intrinsically motivated ("how can I use my learning to better myself') learners with life experiences, who are reflective or theoretical learners. It is suited to subject matter best delivered according to the behaviourist philosophy (stimulus, response, reinforcement). The lecture format may be less helpful for young students who are extrinsically motivated ("what's in it for me"), who have limited life experiences, who are practical or active learners, and who must learn content that doesn't have just one right answer. A constructivist philosophy may be called for in this case, which represents a paradigm shift for students from being passive recipients of instruction that has been designed for them, to being actively involved in 
determining what their own learning needs are and how those needs can best be satisfied. This paper and the preceding workshop offers an opinion of how a theory of motivation can be used to match instructional strategies to learner characteristics.

\section{Discussion}

\section{Learner Characteristics}

The traditional university and college student can be classified as a young adult chronologically; however, due to their limited life experiences and dependence on external motivation (e.g., rewards in the form of grades for work assigned by a teacher in topics not of their choosing) up to this stage in their learning career they are more similar to young learners. The typical university and college student must achieve a university degree to be accepted into their future profession which can be argued does set the conditions for intrinsic motivation (i.e. goals that arise from within), however the case can equally be made for extrinsically motivated students who are aware that a degree or diploma are the entry level qualifications for their future work but who are living in the present and struggling to balance part-time work, parental expectations and the unfamiliar university/college culture potentially limiting their experience to short term goals based on the extrinsic rewards of grades. The differences between intrinsic (self-motivated) and extrinsic (external) motivation are important when choosing suitable reward systems (assessment types and criteria) and instructional strategies (conditions for learning).

\section{Support}

For some university/college students, it is necessary to generate intrinsic motivation to achieve a level of effort justification. Effort justification is the tendency to assign more value to an outcome that one has had to put great effort into achieving (Bandura, 1991). Conversely, outcomes that have rewards assigned by others are less motivating. The social cognitive concept of cognitive evaluation theory (CET) proposed by Eisenberg, Deci, Koestner, \& Ryan (1999), "asserts that underlying intrinsic motivation are the psychological needs for autonomy and competence, so the effects of an event such as a reward depends on how it affects perceived self-determination and perceived competence" ( $p$. 628). This theory is the best way to explain how to achieve efficient and effective learning in this group. The traditional university instructional strategy, less so in colleges, is the lecture method with the traditional reward a grade achieved in exchange for doing a certain amount of work to a certain standard assigned by the professor. While suitable for reflective learners, the lecture method puts those with other learning styles at a disadvantage. Good instructional design should include a selection of instructional strategies to motivate most students most of the time to achieve good academic results. One example is the use of a learning contract that assigns a range of assessments and a range of grades that the students "sign-up" to achieve. A student can contract with the professor at the beginning of the term to receive either an A, a $B$, or a $C$ grade in exchange for predetermined products with quality and quantity described in a rubric. Once the contract is agreed upon between student and teacher, it is up to the student to uphold his or her end of the bargain. The motivation to learn is now placed firmly in the hands of the student. The student decides what level of reward they will receive from their level of effort (effort justification) and learner performance is not undermined by the traditional conditions of the classroom reward system (Eisenberg, Deci, Koestner, \& Ryan, 1999, p. 629). Motivation is increased in a population that, although chronologically classed as "adult", is more similar to younger more extrinsically motivated learners. 


\section{Application}

Effort, performance, and consequence (Weibelzahl and Kelly, (2005), p. 81) is shown in the model below as the output of the learner and the organization (Figure 1). This model reflects the traditional self-directed conditions for learning of attention, effort, participation, and persistence (Garrison, 1997). Students bring their inputs while the learning organization supplies the environmental factors.

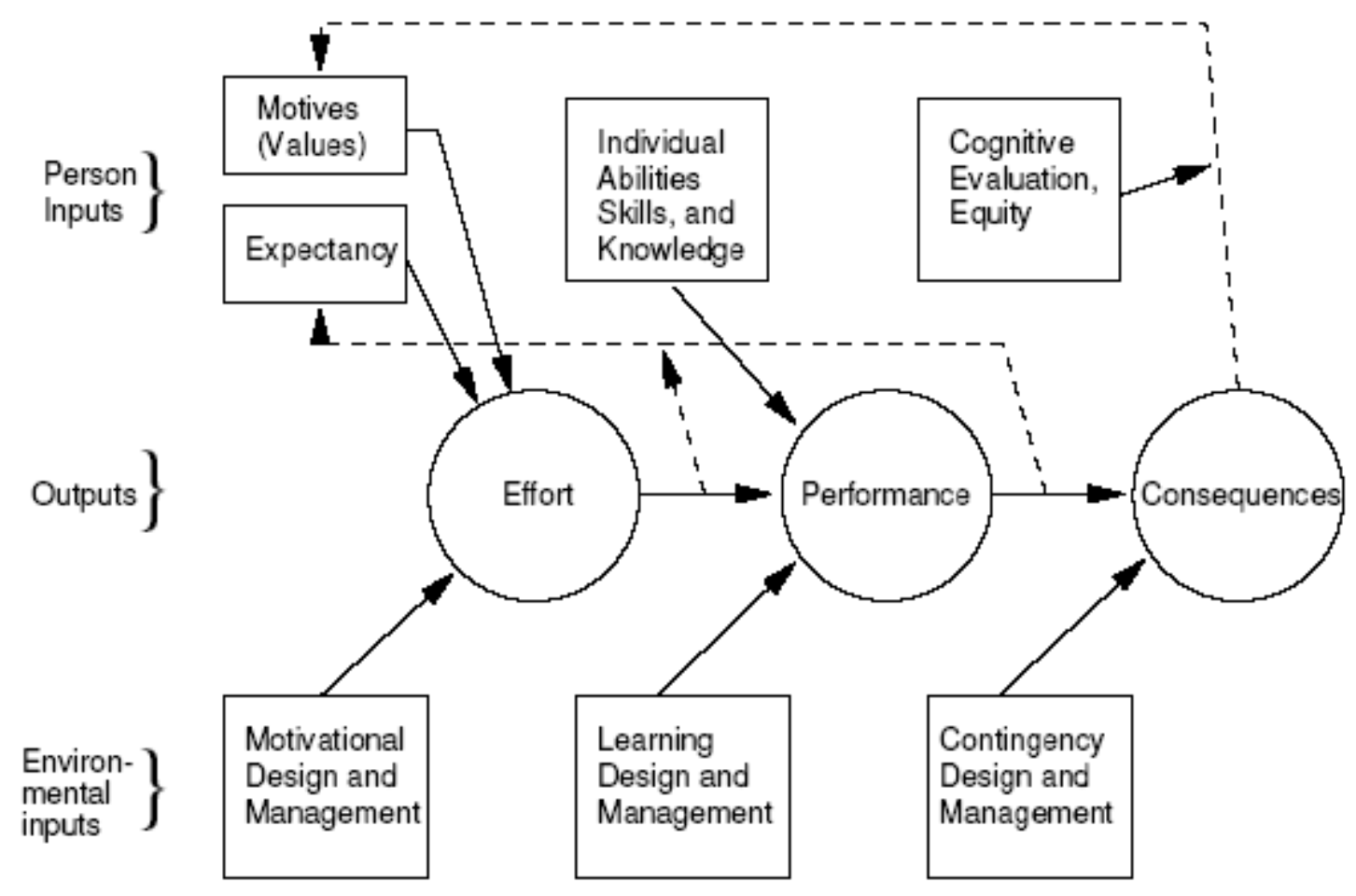

Figure 1

An Adaptation of Motivation Theory by Keller (1983) adapted by de Vincent (2003) in Weibelzahl and Kelly (2005)

\section{Instructional Design to Support Learning Characteristics and Motivation}

The theory and practice of instructional design is complex, however, the SERC Portal for Educators called Pedagogy in Action (accessed through Carleton University's Faculty Development site at http://serc.carleton.edu/sp/library/pedagogies.html ) has an excellent section on Teaching Methods that will apply the environmental factors of motivation, learning, and contingency design and management. If environmental factors are considered to be externally controlled, then expectancy theory fits into this model as an approach to designing for extrinsically motivated learners. It contains 60 content-specific teaching methods that includes a description of the technique, tips for using each technique, research on the technique's impact on learning, and examples. Many of these techniques can be employed in distance learning in education because they support instructional design based on intrinsic motivation based on learner/content interaction 
instead of learner/teacher interaction. What else could motivate a student to self-select a subject that can only be learned independently with minimal input from the teacher? To employ these techniques in a face-to-face setting lends support to the extrinsically motivated learner by providing external conditions for learning based on the internal capabilities of the learner (Gagne, 1974).

\section{Using the ARCS Model in Curriculum Design}

In 1983, John Keller designed the ARCS (Attention, Relevance, Confidence, and Satisfaction) model to help instructors design

\section{Table 1}

\section{ARCS Categories}

\begin{tabular}{llll}
\hline Attention & Relevance & Confidence & Satisfaction \\
\hline A1 Perceptual arousal & R1 Goal orientation & C1 Learning requirements & S1 Intrinsic reinforcement \\
A2 Inquiry arousal & R2 Motive matching & C2 Success opportunities & S2 Extrinsic rewards \\
A3 Variability & R3 Familiarity & C3 Personal control & S3 Equity \\
\hline
\end{tabular}

\section{Workshop}

The conference workshop was held for 30 minutes three consecutive times. Participants were introduced to the model based on the adaptation to Keller's model (the model was printed on large table top sized paper). They discussed the parts of the model that could be influenced by instructional design and agreed that motivation could be one such element. Next, the ARCS Model itself was presented by showing participants a table like the one in Table 1 but with the sub categories missing. The participants worked together to put the correct sub-categories in the correct columns. This process led to a general discussion of the ARCS Model and how Keller created it to foster motivation through instructional design. The participants discussed the characteristics of the typical university or college student and agreed motivating curricula (McConnell, Hoover, \& Sasse, 2001). The subcategories of each part of the model are shown in Table 1. Expectancy theory is the basis of the ARCS Model and suggests that the effort the student puts forth with respect to their learning is dependent on the value that the student places on the task. This is one way of fostering intrinsic motivation. Keller, in his paper titled What Are the ARCS Categories, describes the categories, identifies the design questions, and suggests support strategies. Participants at the Society for Teaching and Learning in Higher Education workshop on which this paper is based followed the same procedure to explore ways to design instruction for the extrinsically motivated learner. 
strategies through the ARCS Model. Many spoke of challenging classroom situations and how consideration of an instructional strategy based on factors other than the content (although the content must also be a factor in good instructional design) would assist them in their approach to design. Toward the end of each session, the participants became engaged in peer to peer discussions aimed at solving particularly challenging design dilemmas. This movement during the workshop from a focus on the facilitator to the content to each other was the goal and a model for good collaborative learning.

\section{Conclusion}

The workshop was an introductory session aimed at showing how the choice of instructional methods and techniques that suit the learners' needs should increase motivation and perhaps achievement. A future research goal is to document the role that increased motivation has in learner achievement. The challenge is to design a study that both evaluates the effectiveness of ARCS course design and measures learner achievement. This will be done by administering the Keller ARCS Course Interest Survey to courses designed with and without the ARCS Model of instructional design. The Keller ARCS Model and the adaptation of it described in this paper and used during the Society for Teaching and Learning in Higher Education Conference 2014 is one potential approach to instructional design. Good instructional design should foster interaction between the learner and the teacher, the learner and the material, and the learner and his or her peers. The design of the workshop was meant to model this approach. During the workshop the participants thought of motivation as a goal to be achieved with instructional design. The ARCS Model is more than 20 years old now; however, its utility remains. The ARCS Model can be used not only to design motivating curricula that draws on students' interests, but it can also be used to base assessments on students' motivational perceptions (McConnell et al., 2001). A workshop with a similar group to explore this use of the model would complement this workshop on motivation and instructional design. A complimentary approach to measuring achievement is the concept of deep learning as described by Entwistle (2012, p. 291). He has developed an assessment instrument called Approaches to Study Skills Inventory for Students (ASSIST) that measures the learning processes involved in a deep approach, as opposed to a surface approach, to learning through study skills. As always, professional instructional designers and learning specialists can provide advice and consultancy on education, training, learning, and professional development.

\section{References}

Bandura, A. (1991). Self-regulation in motivation through anticipatory and self-reflective mechanisms. In R.A. Dienstbier (Ed.), Perspectives on motivation (pp. 69-95). Lincoln, NE: University of Nebraska Press. Retrieved from http://books.google.ca/books ?hl=en\&lr=\&id=veZlIWFOSGgC\&oi=fnd $\& p g=P A 69 \& d q=l e v e l+o f+$ effort + justificatio $\mathrm{n}+\mathrm{in}+$ motivation\&ots=Iq5pV6bzPZ\&sig= D9J9jKrI5E-Kwl3pHaTRDB3YPo4\#v= onepage\&q\&f=false

Eisenberg, N., Deci, E. L., Koestner, R., \& Ryan, R. M. (1999). A meta-analytic review of experiments examining the effects of extrinsic rewards on intrinsic motivation. Psychological Bulletin, 125, 627668.

Entwistle, N. (2012). Approaches to learning and studying. In: Encyclopedia of the Sciences of Learning.

Gagne, R. M. (1974). Instruction and the conditions of learning. In W.M. Bart and M.R. Wong (Eds.), Psychology of school learning: Views of the learner (Volume 1, Environmentalism) (pp. 153-175). New York, NY: MSS Information Corporation. 
Garrison, D. R. (1997). Self-directed learning: Toward a comprehensive model. Adult Education Quarterly, 48, 18-33. http://dx.doi.org/10.1177/0741713697048 00103

Keller, J. M. (n.d.). What are the ARCS categories? Retrieved from http://www.arcsmodel.com/ \#!arcs-categories/clzqp.

McConnell, C., Hoover, G., \& Sasse, C. (2001). Using the ARCS Model to design motivating curriculum. Proceedings of the Academy of Educational Leadership, Volume 6, Number 1, Nashville.

SERC Portal for Educators (n.d.). Pedagogy in action. Carleton University's Faculty Development Site. Retrieved from http://serc.carleton.edu/sp/index.html

Weibelzahl, S., \& Kelly, D. (2005, October). Adaptation to motivational states in educational systems. In: Proceedings of the workshop week Lernen - Wissensentdeckung - Adaptivität (LWA2005), pp. 80-84, Saarland University, Saarbrücken.

\section{Acknowledgement}

Thanks to Dr John Freeman for shaping the narrative of this essay.

\section{Biography}

Catherine Bates is a Doctoral Candidate in Education at Queen's University and a retired Royal Canadian Air Force Training Development Officer. Her areas of interest are motivation, instruction, self-regulation, and immersive environments for learning. Her research involves how to achieve and measure deeper learning using a strategic approach based on selfregulation. 